\title{
Soluble MICB in Plasma and Urine Explains Population Expansions of NKG2D+CD4 T Cells Inpatients with Juvenile-Onset Systemic Lupus Erythematosus
}

\author{
Satoru Hamada ${ }^{1,2}$, Andrea Caballero-Benitez ${ }^{1}$, Kate L. Duran', Anne M. Stevens ${ }^{3,4}$, \\ Thomas Spies ${ }^{1}$, Veronika Groh ${ }^{1 \#}$ \\ ${ }^{1}$ Clinical Research Division, Fred Hutch, Seattle, WA, USA \\ ${ }^{2}$ Department of Pediatrics, Ryukyus University, Okinawa Prefecture, Nishihara, Japan \\ ${ }^{3}$ Division of Rheumatology, Department of Pediatrics, University of Washington Medicine, Seattle, WA, USA \\ ${ }^{4}$ Center for Immunity and Immuno Therapies, Seattle Children's Research Institute, Seattle, WA, USA \\ Email:\#vgroh@fredhutch.org
}

How to cite this paper: Hamada, S., Caballero-Benitez, A., Duran, K.L., Stevens, A.M., Spies, T. and Groh, V. (2017) Soluble MICB in Plasma and Urine Explains Population Expansions of NKG2D ${ }^{+} \mathrm{CD} 4 \mathrm{~T}$ Cells Inpatients with Juvenile-Onset Systemic Lupus Erythematosus. Open Journal of Immunology, 7, 1-17.

https://doi.org/10.4236/oji.2017.71001

Received: January 25, 2017

Accepted: March 26, 2017

Published: March 29, 2017

Copyright $\odot 2017$ by authors and Scientific Research Publishing Inc. This work is licensed under the Creative Commons Attribution International License (CC BY 4.0).

http://creativecommons.org/licenses/by/4.0/

\begin{abstract}
Abnormal NKG2D ligand expression has been implicated in the initiation and maintenance of various auto-inflammatory disorders including systemic lupus erythematosus (SLE). This study's goal was to identify the cellular contexts providing NKG2D ligands for stimulation of the immunosuppressive NKG2D ${ }^{+} \mathrm{CD} 4$ $\mathrm{T}$ cell subset that has been implicated in modulating juvenile-onset SLE disease activity. Although previous observations with $\mathrm{NKG}^{2} \mathrm{D}^{+} \mathrm{CD} 4 \mathrm{~T}$ cells in healthy individuals pointed towards peripheral B cell and myeloid cell compartments as possible sites of enhanced NKG2DL presence, we found no evidence for a disease-associated increase of NKG2DL-positivity among juvenile-onset SLE B cells and monocytes. However, juvenile-onset SLE patient plasma and matched urine samples were positive by ELISA for the soluble form of the NKG2D ligands MICA and MICB, suggesting that kidney and/or peripheral blood may constitute the NKG2DL positive microenvironments driving NKG2D $\mathrm{D}^{+} \mathrm{CD} 4 \mathrm{~T}$ cell population expansions in this disease.
\end{abstract}

\section{Keywords}

NKG2D Ligands, NKG2D ${ }^{+}$CD4 T Cells, Juvenile-Onset Systemic Lupus Erythematosus, B Cells, Monocytes

${ }^{\star}$ Authors contributed equally. 


\section{Introduction}

The NKG2D lymphocyte receptor and its cell stress-induced ligands have been implicated in the initiation and amplification of several autoimmune and inflammatory disorders [1]. In humans, NKG2D is expressed by most natural killer (NK) cells and CD8 T cells, and some CD4 T cells [2] [3]. NKG2D signal via association with the tyrosinemotive-containing DAP10 adapter and, upon ligand binding, stimulates effector functions or proliferation and survival [2] [4] [5]. NKG2D ligands (NKG2DL) include the MHC class I-related chains A and B (MICA, MICB) and six members of the UL-16 binding protein family (ULBP1-6) [6]. Central to the immunobiology of these ligands and, by inference of NKG2D, is the fact that functionally relevant amounts are absent from the surface of most normal cells but induced by mechanisms associated with cellular stress responses and thus frequently present on transformed or infected cells, and at sites of tissue inflammation [7].

Aberrant NKG2DL presence occurs in autoimmune and inflammatory diseases such as rheumatoid arthritis [8], alopecia areata [9], and celiac and Crohn's disease [10] [11]. In all these conditions, ligand engagement of NKG2D on tissue-resident effector lymphocytes promotes cell damage and inflammation. Abnormalities in NKG2D-mediated immune responses have also been implicated in the pathophysiology of systemic lupus erythematosus (SLE), although with immune-modulatory rather than tissue damage-promoting consequences [3]. Juvenile-onset SLE (jSLE) disease activity negatively correlates with population expansions of a normally rare CD4 $\mathrm{T}$ cell subset that expresses NKG2D, is autoreactive, and has immunosuppressive functions [3]. Large numbers of such $\mathrm{NKG} 2 \mathrm{D}^{+} \mathrm{CD} 4 \mathrm{~T}$ cells also occur within cancer tissues where autoantigens and NKG2DL on tumor cells enable NKG2D-costimulated T cell proliferation [12]. With lupus, the ligand-positive cellular contexts providing for NKG2D engagement remain largely unknown. This study aims at addressing this knowledge gap.

\section{Materials and Methods}

\subsection{Subjects and Blood Samples}

19 patients diagnosed before age 18 who fulfilled the American College of Rheumatology criteria for the classification of SLE [13] and age-matched healthy volunteers were included into the study. Patients and healthy volunteers were recruited locally by word of mouth. Demographic characteristics, disease activity and renal disease status, and immunomodulatory medications of all patients are listed in Table 1. Control group demographic data other than age (range 11.8 18) was not available. Peripheral blood, and clinical and laboratory data were collected for each patient and disease activity determined according to the modified SLEDAI Index 2000 [14]. Disease activity scores of five or greater were considered representing active, scores of less than five inactive disease [15] [16]. Sample procurement from jSLE033-122 was between 042006 and 062012; from CIIT1001-20 between 082015 and 012016. Serial samples obtained at times of high or 
Table 1. SLE patient characteristics.

\begin{tabular}{|c|c|c|c|c|c|c|c|}
\hline Subject & $\begin{array}{l}\text { Age at onset } \\
\text { (yr) }\end{array}$ & $\begin{array}{c}\text { Age at draw } \\
(y r)\end{array}$ & Gender & SLEDAI & $\begin{array}{c}\text { Kidney } \\
\text { involvement }\end{array}$ & $\begin{array}{l}\text { Prednisone }{ }^{a} \\
\text { (mg/kg/day) }\end{array}$ & Other immunomodulatory medications $s^{*}$ \\
\hline jSLE033 & 14 & 16.3 & $\mathrm{~F}$ & 22 & Yes & 0.19 & HCQ, Dipyridamole \\
\hline jSLE040 & 7 & 13 & $\mathrm{~F}$ & 18 & Yes & 0.36 & HCG, MMF, Dapsone, CyC, Abatacept \\
\hline jSLE044 & 17 & 19.6 & F & 0 & No & 0.08 & $\mathrm{HCQ}, \mathrm{MMF}$ \\
\hline jSLE049 & 12 & 13.7 & $\mathrm{~F}$ & 2 & No & 0.32 & HCQ \\
\hline jSLE053 & 11 & 13.9 & $\mathrm{~F}$ & 4 & No & None & HCQ \\
\hline jSLE070 & 16 & 15.9 & $\mathrm{~F}$ & 8 & Yes & 1.9 & HCQ, MMF \\
\hline jSLE078 & 12 & 17.2 & $\mathrm{~F}$ & 0 & Yes & None & HCQ, AZT, Dapsone \\
\hline jSLE085 & 15 & 14.9 & $\mathrm{~F}$ & 12 & No & None & None \\
\hline jSLE086a & 11 & 12.7 & $\mathrm{~F}$ & 6 & No & 0.73 & HCQ, MMF \\
\hline jSLE086b & & 13.7 & & 0 & No & None & $\mathrm{HCQ}, \mathrm{MMF}$ \\
\hline jSLE087 & 15 & 16.5 & $\mathrm{~F}$ & 2 & Yes & 0.11 & HCQ, AZT, Mesalamine \\
\hline jSLE090 & 15 & 18.2 & $\mathrm{~F}$ & 4 & Yes & None & None \\
\hline jSLE101a & 16 & 16.5 & $\mathrm{~F}$ & 22 & Yes & 1.23 & HCQ \\
\hline jSLE101b & & 17.6 & & 8 & Yes & 0.1 & HCQ, MMF \\
\hline jSLE105 & 15 & 16.3 & $\mathrm{~F}$ & 7 & No & None & HCQ, MMF \\
\hline jSLE107 & 14 & 17.4 & $\mathrm{~F}$ & 4 & No & None & None \\
\hline jSLE110 & 11 & 11.9 & F & 29 & Yes & 1.56 & HCQ, AZT \\
\hline jSLE112 & 11 & 12.4 & $\mathrm{~F}$ & 4 & No & None & $\mathrm{HCQ}, \mathrm{AZT}$ \\
\hline jSLE114 & 13 & 16.9 & M & 25 & Yes & 0.25 & HCQ, AZT \\
\hline jSLE117a & 14 & 14.8 & $\mathrm{~F}$ & 10 & Yes & 0.24 & HCQ, MMF, Dapsone \\
\hline jSLE117b & & 15.1 & & 0 & Yes & 0.17 & HCQ, MMF, Dapson \\
\hline jSLE122 & 15 & 15.2 & $\mathrm{~F}$ & 9 & No & None & None \\
\hline CIIT1001A & 13 & 15 & $\mathrm{~F}$ & 2 & No & 0.5 & $\mathrm{HCQ}, \mathrm{MMF}$ \\
\hline CIIT1008A & 15 & 18 & $\mathrm{~F}$ & 2 & Yes & 0.2 & HCQ, MMF, Rituximab, Tacrolimus \\
\hline CIIT1003A & 13 & 19 & $\mathrm{~F}$ & 7 & Yes & 0.13 & HCQ, AZT \\
\hline CIIT0203A & 7 & 16 & $\mathrm{~F}$ & 22 & Yes & None & None \\
\hline CIIT1020A & 15 & 15.2 & M & $2^{\mathrm{b}}$ & No & 0.5 & HCQ, MMF \\
\hline
\end{tabular}

aTherapeutic regimens including prednisone $>2 \mathrm{mg} / \mathrm{kg} /$ day and/or mycophenolatemofetil (MMF), cyclophosphamide (Cyc), or azathioprine (AZT) were considered immunosuppressive. HCQ = hydroxychloroquine. ${ }^{b}$ No SLEDAI available; clinically no disease activity, 2 reflects reduced complement levels.

low disease activity were available from three patients. PBMC were isolated as described [3]. Paired urine and plasma samples were collected from an additional 5 jSLE patients (Table 1). All activities were carried out in accordance with the Declaration of Helsinki and approved by local Institutional Review Boards. All subjects provided informed written consent.

\subsection{Polychromatic Flow Cytometry}

PBMC staining and analysis were as described [3]. Unless otherwise specified, mAbs were from BD Pharmingen and included anti-CD3-Alexa Fluor 700 (UCHT1), anti-CD4-APC (RPA-T4), anti-CD8-PacificBlue (RPA-T8), anti-CD11c- 
FITC (BU15, Thermo Scientific), anti-CD14-APC (RMO52, Beckman Coulter), anti-CD16-PacificBlue (3G8), anti-CD19-APC (HIB19) and anti-CD20-FITC (L27), anti-CD56-APC (N901, Beckman Coulter), and anti-NKG2D-PE (1D11; [2]). Anti-NKG2DL mAb were anti-MICA/B-PE (6D4), anti-ULBP1-PE (170818, R \& D Systems), anti-ULBP2/5/6-PE (165903; R \& D Systems), antiULBP3-PE (166510; R \& D Systems), and anti-ULBP4-PE (1H1; [12]). In some cases, viable cell numbers were limiting resulting in partial data sets.

\subsection{Monocyte Stimulation}

Monocytes, enriched from either patient or healthy donor PBMC using classic plastic adherence, were incubated with RMPI-1640/10\% FBS supplemented with LPS (10 $\mu \mathrm{g} / \mathrm{ml}$; Sigma) or GM-CFS (20 ng/ml; R \& D Systems), or with medium alone, for 24 hours and examined for NKG2DL expression by flow cytometry.

\subsection{ELISA for Soluble NKG2D Ligand Detection}

Soluble MICA (sMICA), soluble MICB (sMICB), and soluble ULBP1 (sULBP1) in jSLE patient plasma were determined using ELISA kits (Human MICA and Human MICB; Abcam; Human ULBP-1, R \& D Systems) according to manufacturers' instructions.

\subsection{Statistical Analysis}

Populations were compared using the two-sample $t$-test and significance assigned where $p<0.05$. Contribution of more than one sample by some subjects was accounted for using multivariate logistic generalized estimating equations (GEE). The correlation between $\mathrm{NKG} 2 \mathrm{D}^{+} \mathrm{CD} 4 \mathrm{~T}$ cell frequencies and soluble NKG2DL was estimated from linear regression.

\section{Results}

\subsection{Juvenile-Onset SLE B Cells Express Normal NKG2D Ligand Profiles}

Our previous observation of lupus-associated $\mathrm{NKG} 2 \mathrm{D}^{+} \mathrm{CD} 4 \mathrm{~T}$ cell population expansions was made in patients with the juvenile-onset form of this disease [3]. For consistency, we maintained this disease focus enrolling 19 jSLE patients and 20 healthy age-matched control (HC) donors. Flow cytometry of PBMC samples (altogether 22, since each two serial samples were available from three patients; Table 1) confirmed increased frequencies of $\mathrm{NKG}_{2} \mathrm{D}^{+} \mathrm{CD} 4 \mathrm{~T}$ cells among the jSLE cohort compared to HC $(10.82 \% \pm 8.72 \%$ versus $3.64 \% \pm 2.34 ; p \leq 0.00001)$ with larger proportions of these cells in inactive compared to active disease $(15.99 \%$ $\pm 10.48 \%$ versus $6.12 \% \pm 3.47 ; p=0.0007$ )

In healthy individuals, peripheral blood $\mathrm{B}$ cells provide the autoantigens and NKG2DL necessary for NKG2 $\mathrm{D}^{+} \mathrm{CD} 4 \mathrm{~T}$ cell proliferation [3]. Screening for NKG2DL expression in jSLE thus first focused on the peripheral B cell compartment. Lupus patients, adult and juvenile-onset alike, are lymphopenic and, compared to healthy individuals, have reduced absolute B cell counts [17]. Accom- 
modating these contractions and the typically small volumes of pediatric blood draws we started out with an exploratory flow cytometry analysis that defined B cells based only on CD19 and CD20 coexpression without consideration of additional functionally relevant markers. NKG2DL were tested as a third parameter using mAbs to MICA/B, ULBP1, ULBP2/5/6, ULBP3, and ULBP4 (Supplementary Figure $\mathrm{S} 1$ displays examples of gating strategy and primary data). $\mathrm{CD} 19^{+} \mathrm{CD} 20^{+} \mathrm{B}$ cells were present in all but one (jSLE114) of the 22 jSLEPBMC samples with absolute counts lower than those described for healthy children $(219.8 \pm 282.4$ cells/ $\mu$ l; [17] [18]). Relative proportions of $\mathrm{CD} 19^{+} \mathrm{CD} 20^{+}$cells were larger than those of the control donors (mean $13.6 \% \pm 11.3$ versus $7.6 \% \pm 4.7 ; p=0.0187$ ) but independent of disease activity (Figure 1(a)).

NKG2DL expression profiles of jSLE B cells displayed pronounced individual variability and, overall, were similar to those recorded with HC (Figure 1(b) and Figure 1(c); [19] [20]). In both cohorts, ULBP ligands (except ULBP4) were more prevalent than MICA/B. B cells expressing at least one, and most of the time two or more NKG2DL were present in all samples, albeit in $~ 50 \%$ of jSLE and $\mathrm{HC}$ samples their frequencies were low $\left(<10 \%\right.$ of total $\mathrm{CD} 19^{+} \mathrm{CD} 20^{+}$cells). $10 \%$ or more NKG2DL-positive B cells were detected in 11 jSLE patients and 7 HC. In most samples, two or more NKG2DL were expressed at similar frequencies suggesting coordinate expression of more than one ligand by a given cell (Figure 1(b)). Indeed, co-staining for ULBP1 and ULBP2/5/6 confirmed co-expression of these ligands on $\mathrm{CD} 19^{+} \mathrm{CD} 20^{+} \mathrm{B}$ cells in three additional healthy donor PBMC samples (data not shown). There were no correlations between frequencies of NKG2DL-positive $\mathrm{B}$ cells and frequencies of NKG2D ${ }^{+} \mathrm{CD} 4 \mathrm{~T}$ cells (data not shown). Thus although, as with normal B cells, jSLE B cells, if NKG2DL-positive, may well contribute to $\mathrm{NKG}^{+} \mathrm{D}^{+} \mathrm{CD} 4 \mathrm{~T}$ cell proliferation, it seems unlikely that the jSLEB cell compartment alone provides the NKG2DL abundance presumed necessary for the extensive proliferative expansions of NKG2D+CD4 T cell populations that occur in jSLE [3].

\subsection{Reduced Frequencies of NKG2D Ligand-Positive Cells among Juvenile-Onset SLE Monocyte Populations}

NKG2DL are present on normal monocytes presumably contributing to regulatory crosstalk with NKG2D+ lymphocytes [19] [20] [21] [22]. With no evidence for aberrant NKG2DL presence among lupus B cells we thus considered myelomonocytic cells as possible NKG2DL source for NKG2D ${ }^{+} \mathrm{CD} 4 \mathrm{~T}$ cell activation and expanded the flow cytometry-based screen to lupus monocytes. All but one (jSLE044; excluded due to limiting cell numbers) patient and control PBMC samples were tested. Monocytes were classified as classical, intermediate, and nonclassical subsets based on expression of CD14 and CD16 (Supplementary Figure S2; [23]). Proportions of classical $\left(\mathrm{CD} 14^{\text {bright }} \mathrm{CD} 16^{-}\right)$monocytes were decreased, and those of intermediate $\left(\mathrm{CD} 14^{\text {bright }} \mathrm{CD} 16^{+}\right)$increased in jSLE compared to control samples; non-classical $\left(\mathrm{CD} 14^{\mathrm{dim}} \mathrm{CD} 16^{+}\right)$monocytes were similar in both groups (Figures 2(a)-(c); [24]). None of these changes correlated with disease 


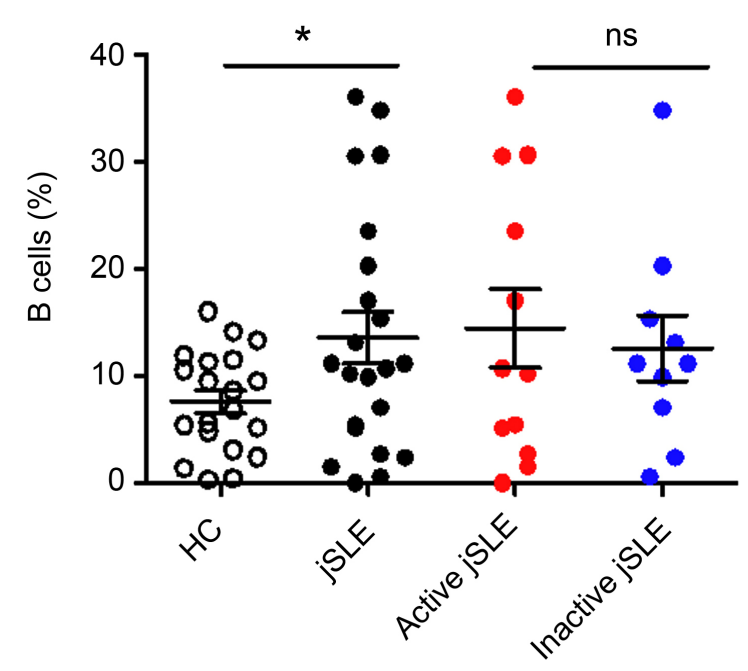

(a)

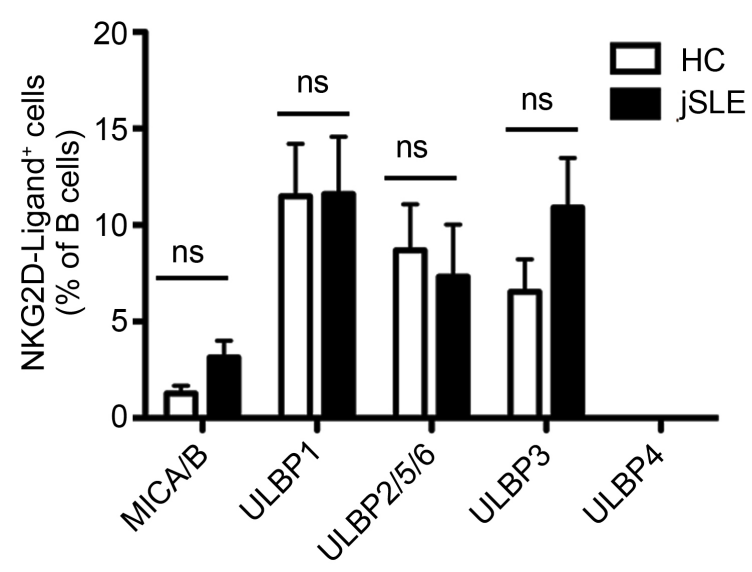

(c)
ID

\begin{tabular}{|c|c|c|c|c|}
\hline HC1 & 1 & 7 & 1 & 0 \\
\hline HC2 & 0 & 1 & 0 & 0 \\
\hline HC3 & 1 & 2 & 2 & 5 \\
\hline HC4 & 0 & 1 & 2 & 1 \\
\hline HC5 & 1 & 2 & 4 & 9 \\
\hline HC6 & 0 & 2 & 4 & 6 \\
\hline $\mathrm{HC} 7$ & 0 & 3 & 3 & 5 \\
\hline HC8 & 1 & 33 & 17 & 4 \\
\hline HC9 & 1 & 4 & 2 & 4 \\
\hline 10 & & 4 & 3 & - \\
\hline
\end{tabular}

$\begin{array}{llllll}\text { HC11 } & 1 & 3 & 1 & 2 & 0\end{array}$

$\begin{array}{llllll}\text { HC12 } & 9 & 41 & 36 & 33 & 0\end{array}$

$\begin{array}{llllll}\text { HC13 } & 2 & 12 & 23 & 6 & 0\end{array}$

$\begin{array}{llllll}\mathrm{HC} 14 & 1 & 5 & 2 & 3 & 0\end{array}$

$\begin{array}{llllll}\text { HC15 } & 2 & 6 & 2 & 6 & 0\end{array}$

$\begin{array}{llllll}\text { HC16 } & 1 & 41 & 35 & 26 & 0\end{array}$

$\begin{array}{llllll}\text { HC17 } & 1 & 30 & 25 & 7 & 0\end{array}$

$\begin{array}{llllll}\text { HC18 } & 1 & 8 & 2 & 3 & 0\end{array}$

$\begin{array}{llllll}\text { HC19 } & 2 & 12 & 6 & 6 & 0\end{array}$

$\begin{array}{llllll}\text { HC20 } & 0 & 11 & 1 & 1 & 0\end{array}$

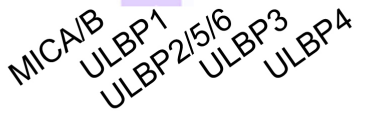

(b)
ID

$\begin{array}{llllllll}\text { jSLE033 } & 16 & 74 & 63 & 60 & 0\end{array}$

$\begin{array}{llllll}\text { jSLE040 } & 2 & 7 & 5 & 12 & 0\end{array}$

$\begin{array}{lllllll}\text { jSLE044 } & 10 & 18 & 7 & 12 & 0\end{array}$

$\begin{array}{llllll}\text { jSLE049 } & 3 & 7 & 4 & 11 & 0\end{array}$

$\begin{array}{llllll}\text { jSLE053 } & 1 & 10 & 3 & 6 & 0\end{array}$

$\begin{array}{llllll}\text { jSLE070 } & 0 & 2 & 2 & 5 & 0\end{array}$

jSLE078 $14 \quad 25 \quad 29 \quad 30 \quad 0$

$\begin{array}{llllll}\text { jSLE085 } & 2 & 7 & 3 & 8 & 0\end{array}$

$\begin{array}{llllll}\text { jSLE086a } & 1 & 6 & 2 & 15 & 0\end{array}$

$\begin{array}{lllllll}\text { jSLE086b } & 0 & 1 & 1 & 6 & 0\end{array}$

\begin{tabular}{lllll|l} 
jSLE087 & 2 & 14 & 4 & 0
\end{tabular}

$\begin{array}{llllll}\text { jSLE090 } & 2 & 17 & 7 & 6 & 0\end{array}$

$\begin{array}{llllll}\text { jSLE0101a } & 1 & 5 & 3 & 4 & 0\end{array}$

$\begin{array}{llllll}\text { jSLE0101b } & 1 & 10 & 2 & 5 & 0\end{array}$

$\begin{array}{llllll}\text { jSLE0105 } & 0 & 2 & 2 & 6 & 0\end{array}$

$\begin{array}{llllll}\text { jSLE0107 } & 1 & 9 & 1 & 5 & 0\end{array}$

$\begin{array}{llllll}\text { jSLE0110 } & 0 & 12 & 6 & 16 & 0\end{array}$

$\begin{array}{lllllll}\text { jSLE0112 } & 3 & 8 & 2 & 7 & 0\end{array}$

jSLE0114

$\begin{array}{llllll}\text { jSLE0117a } & 4 & 5 & 3 & 4 & 0\end{array}$

jSLE0117b 11602220

jSLE0122 $4 \begin{array}{lllll}4 & 3 & 3 & 0\end{array}$

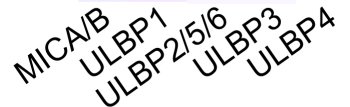

Figure 1. Frequencies and NKG2DL phenotypes of peripheral blood B cells in juvenile-onset SLE patients and healthy controls (HC). (a) Comparisons of proportions (\% of total lymphocytes) of B cells in HC to those in jSLE patients, and between active and inactive disease. Horizontal lines and error bars show median and interquartile range. (b) Heat map display of proportions (numbers in individual squares) of B cells expressing the indicated NKG2D ligands in each patient and control sample. Light grey indicates no data; bar displays color grading; (ID) identification. (c) Graphic display of proportions of B cells expressing the indicated ligands. (a)-(c) ${ }^{*} p<0.05$; (ns) not significant.

activity scores (Figures 2(a)-(c)).

As with jSLEB cells, NKG2DL profiles of patient monocytes resembled the normal expression pattern with substantial variability among individuals and at least one, and frequently two or more ligands expressed (Figure 3(a) and Figure 3(b)). Unlike with B cells, however, all patient monocyte populations differed from controls in the extent to which NKG2DL, and in particular MICA/B and ULBP1, were expressed (Figures 3(a)-(e)). jSLE monocyte populations contained, in part significantly, lower frequencies of ULBP1 positive cells than their corresponding 


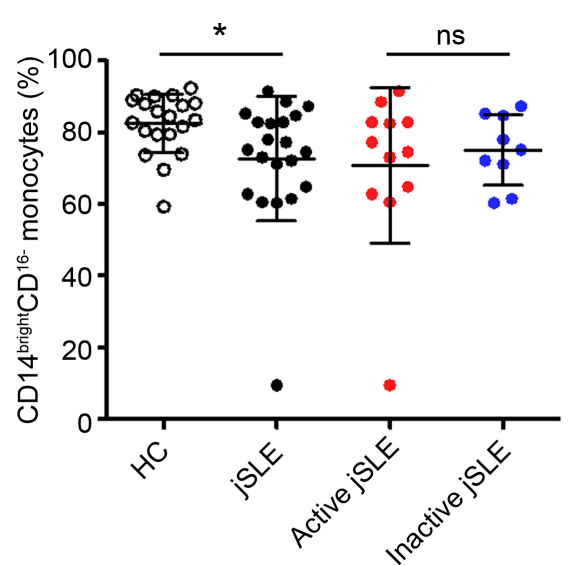

(a)

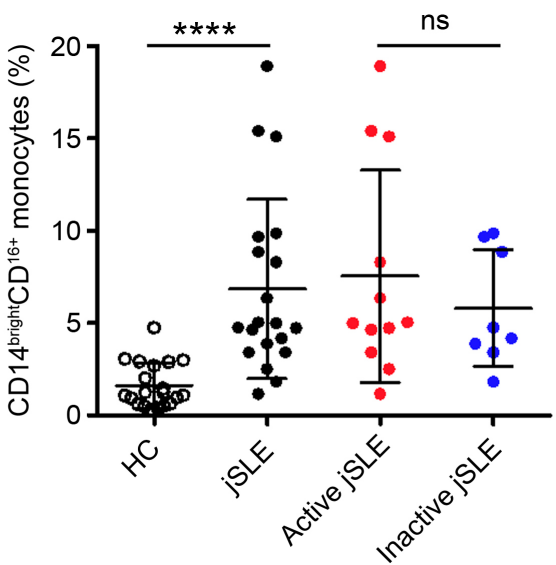

(b)

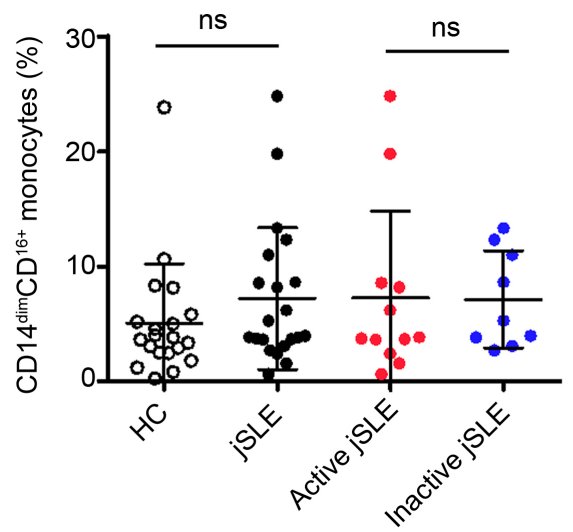

(c)

Figure 2. Frequencies of peripheral blood monocytes in juvenile-onset SLE patients and healthy controls (HC). (a)-(c) Comparisons of proportions (\% of total CD14 ${ }^{+}$cells) of (a) $\mathrm{CD} 14^{\text {bright }} \mathrm{CD} 16^{-}$, (b) $\mathrm{CD} 14^{\text {bright }} \mathrm{CD} 16^{+}$, and (c) $\mathrm{CD} 14^{\text {dim }} \mathrm{CD} 16^{+}$monocytes in $\mathrm{HC}$ to those in jSLE patients, and between active and inactive disease. Horizontal lines and error bars show median and interquartile range; ${ }^{*} p<0.05 ;{ }^{* * *} p<0.0001$; (ns) not significant.

controls. MICA/B positive cells were less frequent among the classical $\mathrm{CD} 14^{\text {bright }} \mathrm{CD} 16^{-}$and intermediate $\mathrm{CD} 14^{\text {bright }} \mathrm{CD} 16^{+}$monocyte subsets compared to controls. Cells expressing ULB2/5/6 or ULBP3 were generally rare but slightly more frequent among jSLE CD14 ${ }^{\mathrm{dim}} \mathrm{CD} 16^{+}$monocytes. Thus, unlike with B cells, jSLE monocytes displayed disease-associated NKG2DL phenotypes although none correlated with disease activityor kidney involvement (data not shown). Due to limiting sample sizes testing of ULBP4 expression was sporadic.

Lupus antigen presenting cells have functional impairments such as an inability to induce the immuneregulatory ligands PD-L1 and CD80 [25] [26]. The apparent lack of ULBP1 and/or MICA/B expression on most jSLE monocytes cells may reflect a similar defect. Hence, adherence-enriched jSLE and control monocytes were cultured in the presence of stimuli known to induce NKG2DL in normal myeloid cells and monitored for surface NKG2DL expression over time [19] [20] [21]. GM-CSF or LPS treatment resulted in induction of MICA/B and ULBP1 in normal controls but had no effect with jSLE monocytes (Supplementary Figure S3; [19] [20] [21]). ELISA of culture supernatants for soluble NKG2DL 


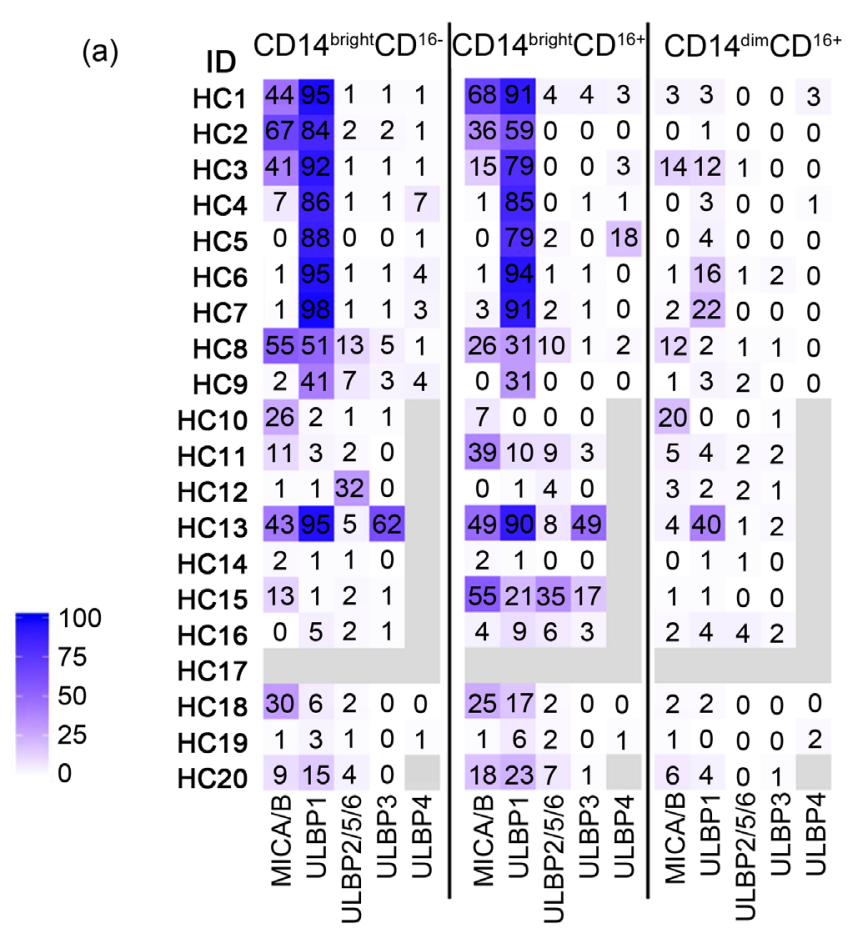

(b) ID ID $\mathrm{CD}^{\text {bright }} \mathrm{CD}^{16}$ jSLE033 000000 jSLE040 53655114 jSLE044

jSLE049 $01113 \quad 1 \quad 1$ jSLE053 01768 jSLE070 $007 \begin{array}{llll}7 & 5 & 1\end{array}$ jSLE078 38332003 jSLE085 $99 \begin{array}{llll}3 & 2 & 1 & 8\end{array}$ $\begin{array}{llllll}\text { jSLE086a } & 2 & 4 & 2 & 1 & 4\end{array}$ jSLE086b 313131113 jSLE087 006002 jSLE090 0011110

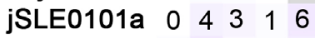
jSLE0101b $1 \begin{array}{llll}6 & 2 & 1 & 5\end{array}$ $\begin{array}{llllll}\text { jSLE0105 } & 1 & 2 & 3 & 1 & 1\end{array}$ jSLE0107 $004 \begin{array}{llll} & 4 & 1\end{array}$ jSLE0110 $0225 \quad 1$ jSLE0112 21041 $\begin{array}{llllll}\text { jSLE0114 } & 1 & 2 & 1 & 1 & 5\end{array}$ jSLE0117a 3301 jSLE0117b $3 \quad 3 \quad 6 \quad 1$ jSLE0122 1221400

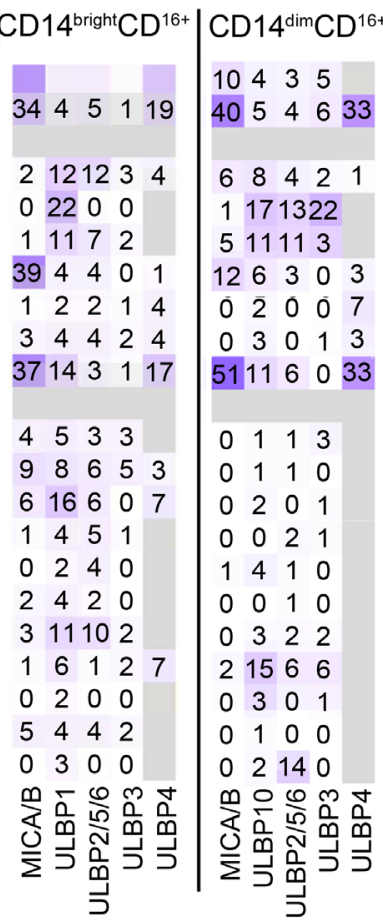

(c)

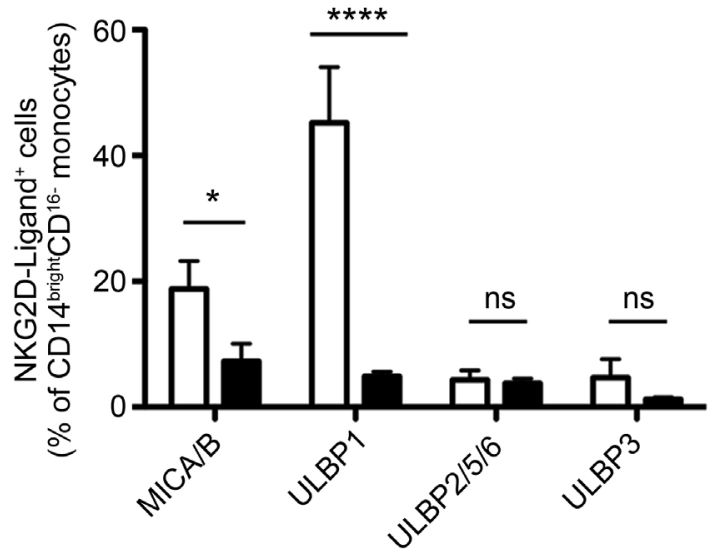

(d)

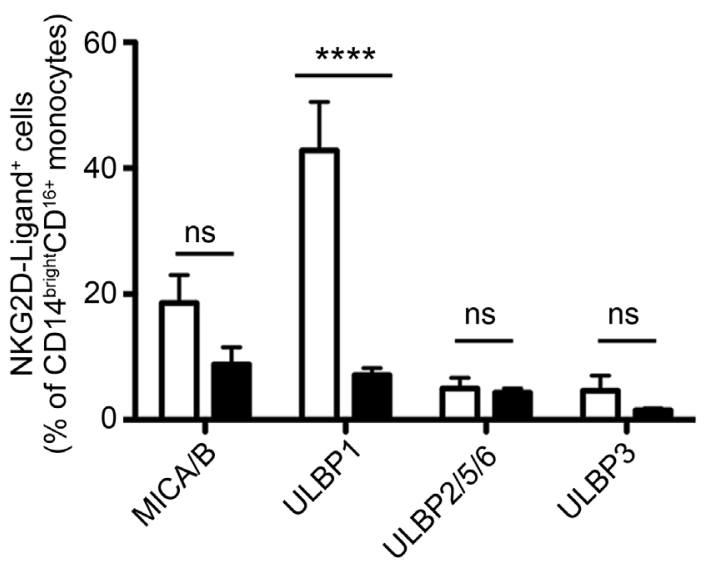

(e)

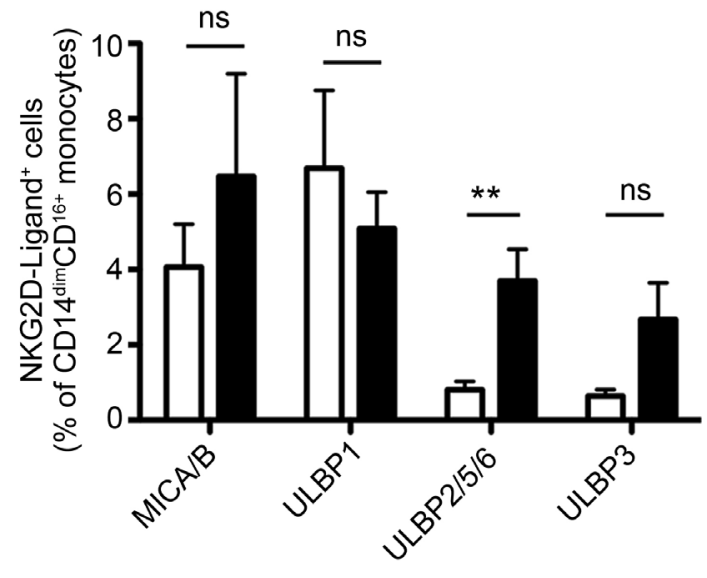

Figure 3. NKG2DL phenotypes of peripheral blood monocytes in juvenile-onset SLE patients and healthy controls (HC). (a) (b) Heat map display of proportions (numbers in individual squares) of CD14/CD16-defined monocytes expressing the indicated ligands in each HC (a) or jSLE patient (b) sample. Bars display color grading. Light grey indicates no data; (ID) identification. (c)-(e) Graphic display of proportions (in \%) of (c) $\mathrm{CD} 14^{\text {bright }} \mathrm{CD} 16^{-}$, (d) $\mathrm{CD} 14^{\text {bright }} \mathrm{CD} 16^{+}$, and (e) CD $14^{\text {dim }} \mathrm{CD} 16^{+}$monocytes expressing the indicated ligands. Open and black bars represent data from HC and patients, respectively. ${ }^{\star} p<0.05 ;{ }^{\star \star} p<0.01 ;{ }^{\star \star \star \star} p$ $<0.0001$; (ns) not significant.

(sMICA, sMICB, sULBP1) was negative suggesting that the lack of surface NKG2DL on the jSLE monocytes was not due to enhanced ligand shedding [27]. Thus 
altogether, as with lupus B cells, lupus monocytes unlikely provide NKG2DL driving $\mathrm{NKG}_{2} \mathrm{D}^{+} \mathrm{CD} 4 \mathrm{~T}$ cell proliferation. To ensure comprehensiveness, we also examined patient and control $\mathrm{T}$ cell and $\mathrm{NK}$ cell compartments for NKG2DL expression. Rare $(<5 \%)$ NKG2DL-positive CD4 and CD8 T cells were detected in both cohorts with no prevalence for one or the other. NK cells (defined based on expression of CD56 and/or CD16) were NKG2DL-negative (data not shown).

\subsection{Soluble MICB in Juvenile-Onset SLE Plasma and Urine Aligns with Frequencies of NKG2D+CD4 T Cells}

Continuing the search for NKG2DL positive environments we resorted to screening for presence of soluble NKG2DL in matched jSLE patient plasma as surrogate readout for NKG2DL expression elsewhere [3] [12]. Although our earlier study found no significant association between frequencies of NKG2D ${ }^{+} \mathrm{CD} 4 \mathrm{~T}$ cells and soluble MICA (sMICA) plasma concentrations we revisited this issue and extended the analysis to other soluble NKG2DL. Plasma samples matching all 22 patient PBMC specimens were screened by ELISA for sMICA, sMICB, and sULBP1. 14 of these samples were positive for sMICA yet concentrations generally low (picogram range) and unaligned with $\mathrm{NKG}_{2} \mathrm{D}^{+} \mathrm{CD} 4 \mathrm{~T}$ cell frequencies (data not shown). sMICB was detectable in all 22 plasma samples at concentrations that varied widely (range: $199 \mathrm{pg} / \mathrm{ml}-30.3 \mathrm{ng} / \mathrm{ml}$ ) among samples and displayed a significant positive trend relationship with $\mathrm{NKG}_{2} \mathrm{D}^{+} \mathrm{CD} 4 \mathrm{~T}$ cell proportions (Figure 4(a)). sMICB plasma values also correlated negatively with disease activity scores suggesting clinical relevance (Figure 4(b)). ELISA for sULBP1 was negative throughout. Although sMICB plasma values were independent of presence or absence of overt renal disease we considered kidney as the most likely site of aberrant NKG2DL expression and putative origin of NKG2DL shedding [28]. Because of lack of access to kidney biopsies we examined patient urine instead for the presence of soluble NKG2DL (sMICA, sMICB, and sULBP1). Urine specimens matching the 22 patient and 20 control PBMC and plasma were not available. We thus examined urine and paired plasma from an additional five jSLE patients (Table 1) and age-matched controls by sMICA and sMICB ELISA. All patient-but none of the HC-derived samples were positive for SMICB with concentrations in the two specimen types well aligned (Figure 4(c)). sMICA was detected in all jSLE urine samples and in three of the paired plasmas (Figure $4(c))$. Extending these observations to adult lupus, paired urine and plasma specimens from three SLE patients also contained low concentrations of sMICA and abundant sMICB. ELISA for sULBP1 was negative throughout. Filtration of plasma sMICA/B in the kidney is unlikely as control urine samples from patients with MICA/B expressing tumors and abundant plasma sMICA/B were negative for sNKG2DL (data not shown). Altogether, these results point towards the kidney as the site of aberrant NKG2DL expression in jSLE with both cell surface and soluble ligands possibly driving the $\mathrm{NKG}_{2} \mathrm{D}^{+} \mathrm{CD} 4 \mathrm{~T}$ cell population expansions typical for this disease. 


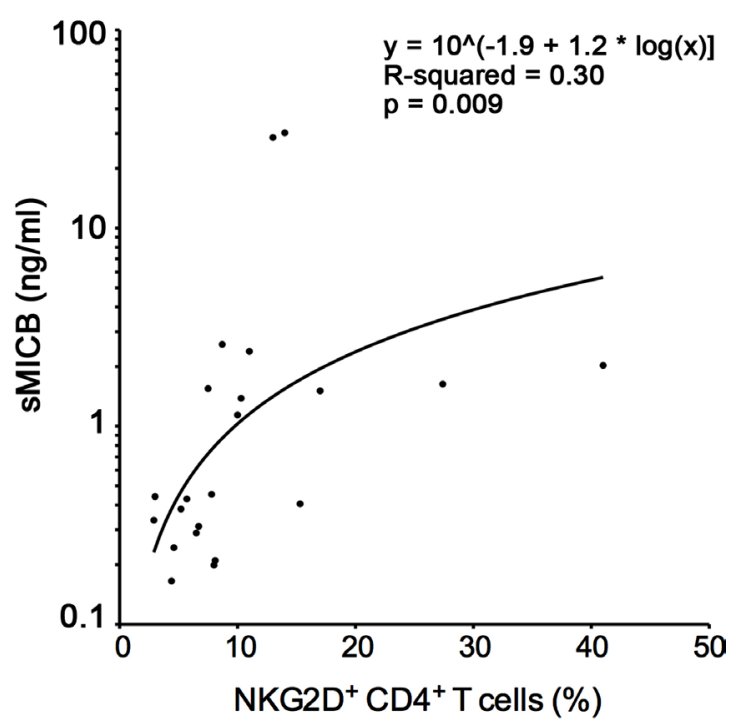

(a)

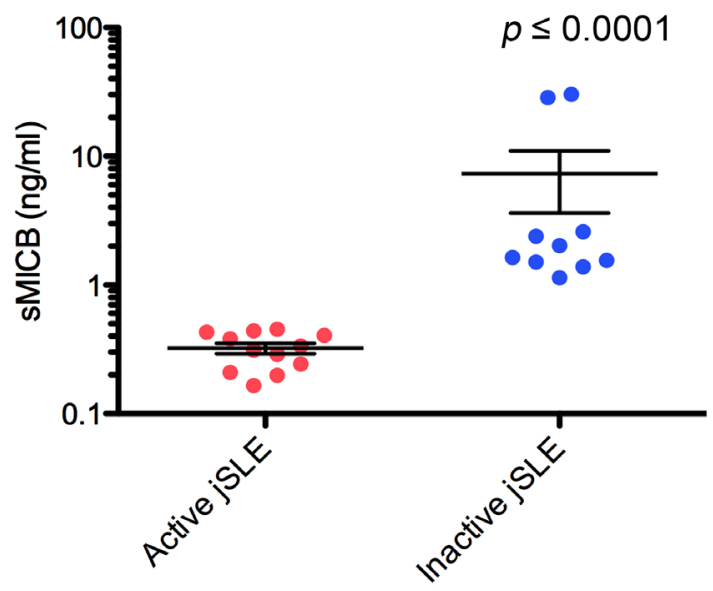

(b)

\begin{tabular}{c|c|c|c|c|}
\hline Patient ID & \multicolumn{2}{|c|}{ soluble MICA (pg/mI) } & \multicolumn{2}{c|}{ soluble MICB (pg/mI) } \\
\hline & urine & plasma & urine & plasma \\
\hline CIIT1001A & 240 & 110 & 4840 & 3980 \\
\hline CIIT1008A & 92 & 147 & 2590 & 2160 \\
\hline CIIT1003A & 270 & $<27$ & 700 & 820 \\
\hline CIIT0203A & 45 & $<27$ & 270 & 350 \\
\hline CIIT1020A & 42 & 31 & 1430 & 1090 \\
\hline
\end{tabular}

(c)

Figure 4. Presence of soluble MICB in plasma and urine from juvenile-onset SLE patients. (a) Overall data point distribution and statistical evaluation $(y=10 \wedge[-1.9+1.2$ * $\log (\mathrm{x})]$, R-squared $=0.3 ; \mathrm{p}=0.009)$ of soluble MICB plasma concentrations $(\mathrm{ng} / \mathrm{ml} ; \log$ scale) in relationship to frequencies of $\mathrm{NKG}_{2} \mathrm{D}^{+} \mathrm{CD} 4 \mathrm{~T}$ cells in the 22 jSLE patient samples studied. (b) Comparisons of soluble MICB plasma concentrations ( $\mathrm{ng} / \mathrm{ml}$; log scale) in jSLE patients with active disease to those of patients with inactive disease. Horizontal lines and error bars show median and interquartile range. (c) Tabulation of soluble MICA and soluble MICB concentrations $(\mathrm{pg} / \mathrm{ml})$ in urine and paired plasma from five jSLE patients. Patient ID = jSLE patient identification.

\section{Discussion}

Aberrant NKG2DL presence is thought to be relevant in lupus disease regulation 
but the tissues and cell types involved have not been defined [3] [28] [29] [30]. This study's goal was to identify the cellular contexts that might provide NKG2DL for stimulation of the immunosuppressive $\mathrm{NKG}_{2} \mathrm{D}^{+} \mathrm{CD} 4 \mathrm{~T}$ cell subset that has been implicated in modulating jSLE disease activity [3]. Although earlier observations with $\mathrm{NKG} 2 \mathrm{D}^{+} \mathrm{CD} 4 \mathrm{~T}$ cells in healthy individuals pointed towards the $\mathrm{B}$ cell compartment as possible site of enhanced NKG2DL presence, there was no evidence for a disease-associated increase of NKG2DL-positivity among jSLE B cells. This was somewhat unexpected, as NKG2DL induction among lupus B cells would be consistent with NKG2D-mediated co-stimulation driving proliferative expansions of autoreactive and B cell antigen-specific NKG2D+CD4 T cell populations [3]. jSLE monocytes, largely devoid of NKG2DL, also emerged as unlikely source of NKG2DL-mediated NKG2D ${ }^{+} \mathrm{CD} 4 \mathrm{~T}$ cell stimulation. However, patient plasma and matched urine samples were positive by ELISA for the soluble form of MICA and MICB, suggesting that kidney and/or peripheral blood might constitute the NKG2DL positive microenvironment driving NKG2D ${ }^{+} \mathrm{CD} 4$ $T$ cell population expansions [3] [12]. Positive trend relationships between sMICB plasma concentrations and proportions of NKG2 $\mathrm{D}^{+} \mathrm{CD} 4 \mathrm{~T}$ cells support this notion [12]. Moreover, sMICB values were inversely correlated with disease activity. As with an earlier study, sMICA plasma concentrations were independent of $\mathrm{NKG}_{2} \mathrm{D}^{+} \mathrm{CD} 4 \mathrm{~T}$ cell frequencies possibly due to masking of ELISA by antiMICA autoantibodies [3]. However, why such a mechanism would preferentially affect MICA over MICB remains unexplained. Whether or not the apparent quantitative prevalence of SMICB compared to sMICA reflects a true biological phenomenon or simply differential sensitivities of the respective ELISA remains equally unknown [28]. NKG2DL expression in, and shedding from jSLE kidney in the absence of overt nephritis is not surprising as even subclinical alterations of tissue homeostasis can lead to induction of NKG2DL expression [7].

The lack of and/or failure to induce MICA/B and/or ULBP1 in jSLE monocytes is consistent with current concepts of lupus-related myeloid cell abnormalities [24] [25] [26]. However, enhanced cell segregation to inflammatory sites may also contribute to the reduced ULBP1- and/or MICA/B-positivity cells among jSLE monocytes, as sequestration of myeloid cells to renal tissue has been described for patients with active lupus nephritis [23] [31]. However, we found no correlation between frequencies of NKG2DL-positive monocytes and presence or absence of renal disease. Arguing against immune-mediated depletion via auto-anti-antibodymediated cytotoxicity, viability of peripheral blood cells from healthy donors was unaffected by incubation with active jSLE patient sera (data not shown). Medication effects on NKG2DL are unlikely as use of immunosuppressive drugs was comparable among all patients (Table $1 ;$ [25]).

In addition to the disease-related changes, this study uncovered a previously underappreciated inter-individual variability in NKG2DL expression by peripheral blood B cells and monocytes [19] [20].

\section{Conclusion}

In summary, although our study does offer insights into the distribution of 
NKG2DL in juvenile-onset lupus patients, it fails to directly pinpoint the precise tissue source for the soluble NKG2DL present in patient plasma and urine. An additional limitation is the relatively small number of matched plasma and urine samples studied. Analysis of a larger patient cohort including more extensive serial sampling is thus desirable as it may lead to the identification of soluble NKG2DL in urine as a disease activity biomarker.

\section{Acknowledgements}

We thank Isaac Jenkins for statistical support, Jianqiang Li for assistance with flow cytometry, Jeffrey Delrow and Ryan Basom for creating the heat map displays, and Helen Crawford for figure preparation.

\section{Funding}

This work was supported by the Children's Cancer Association Japan [SH]; the Arthritis Foundation of America [AMS]; the Lupus Research Institute [AMS, VG]; and grants from the National Institutes of Health [AMS, TS].

\section{References}

[1] Van Belle, T.L. and von Herrath, M.G. (2009) The Role of the Activating Receptor NKG2D in Autoimmunity. Molecular Immunology, 47, 8-11.

[2] Bauer, S., Groh, V., Wu, J., Steinle, A., Phillips, J.H., et al. (1999) Activation of NK Cells and T Cells by NKG2D, a Receptor for Stress-Inducible MICA. Science, 285, 727-729. https://doi.org/10.1126/science.285.5428.727

[3] Dai, Z., Turtle, C.J., Booth, G.C., Booth, G.C., Riddell, S.R., et al. (2009) Normally Occurring NKG2D ${ }^{+} \mathrm{CD} 4{ }^{+} \mathrm{T}$ Cells Are Immunosuppressive and Inversely Correlated with Disease Activity in Juvenile-Onset Lupus. The Journal of Experimental Medicine, 206, 793-805. https://doi.org/10.1084/jem.20081648

[4] Groh, V., Rhinehart, R., Randolph-Habecker, J., Topp, M., Riddell, S.R., et al. (2001) Co-Stimulation of CD8 Alphabeta T Cells by NKG2D via Engagement by MIC Induced on Virus-Infected Cells. Nature Immunology, 2, 255-260. https://doi.org/10.1038/85321

[5] Upshaw, J.L. and Leibson, P.J. (2006) NKG2D-Mediated Activation of Cytotoxic Lymphocytes: Unique Signaling Pathways and Distinct Functional Outcomes. Seminars in Immunology, 18, 167-175.

[6] Eagle, R.A. and Trowsdale, J. (2007) Promiscuity and the Single Receptor: NKG2D. Nature Reviews Immunology, 7, 737-744. https://doi.org/10.1038/nri2144

[7] Raulet, D.H., Gasser, S., Gowen, B.G., Deng, W. and Jung, H. (2013) Regulation of Ligands for the NKG2D Activating Receptor. Annual Review of Immunology, 31, 413-441. https://doi.org/10.1146/annurev-immunol-032712-095951

[8] Groh, V., Bruhl, A., El-Gabalawy, H., Nelson, J.L. and Spies, T. (2003) Stimulation of T Cell Autoreactivity by Anomalous Expression of NKG2D and Its MIC Ligands in Rheumatoid Arthritis. Proceedings of the National Academy of Sciences, 100, 9452-9457. https://doi.org/10.1073/pnas.1632807100

[9] Xing, L., Dai, Z., Jabbari, A., Cerise, J.E., Higgins, C.A., et al. (2014) Alopecia Areata Is Driven by Cytotoxic T Lymphocytes and Is Reversed by JAK Inhibition. Nature Medicine, 20, 1043-1049. https://doi.org/10.1038/nm.3645

[10] Meresse, B., Chen, Z., Ciszewski, C., Tretjakowa, M., Bhagat, G., et al. (2004) Coor- 
dinated Induction by IL15 of a TCR-Independent NKG2D Signaling Pathway Converts CTL into Lymphokine-Activated Killer Cells in Celiac Disease. Immunity, 21, 357-366.

[11] Allez, M., Tieng, V., Nakazawa, A., Treton, X., Pacault, V., et al. (2007) CD4+NKG2D+ T Cells in Crohn's Disease Mediate Inflammatory and Cytotoxic Responses through MICA Interactions. Gastroenterology, 132, 2346-2358.

https://doi.org/10.1053/j.gastro.2007.03.025

[12] Groh, V., Smythe, K., Dai, Z. and Spies, T. (2006) Fas-Ligand-Mediated Paracrine T Cell Regulation by the Receptor NKG2D in Tumor Immunity. Nature Immunology, 7, 755-762. https://doi.org/10.1038/ni1350

[13] Hochberg, M.C. (1997) Updating the American College of Rheumatology Revised Criteria for the Classification of Systemic Lupus Erythematosus. Arthritis \& Rheumatology, 40, 1725. https://doi.org/10.1002/art.1780400928

[14] Gladman, D.D., Ibanez, D. and Urowitz, M.B. (2002) Systemic Lupus Erythematosus Disease Activity Index 2000. The Journal of Rheumatology, 29, 288-291.

[15] Moroni, G., Quaglini, S., Maccario, M., Banfi, G. and Ponticelli, C. (1996) "Nephritic Flares" Are Predictors of Bad Long-Term renal Outcome in Lupus Nephritis. Kidney International, 50, 2047-2053. https://doi.org/10.1038/ki.1996.528

[16] Boumpas, D.T. and Balow, J.E. (1998) Outcome Criteria for Lupus Nephritis Trials: A Critical Overview. Lupus, 7, 622-629. https://doi.org/10.1191/096120398678920758

[17] Arce, E., Jackson, D.G., Gill, M.A., Bennett, L.B., Banchereau, J., et al. (2001) Increased Frequency of Pre-Germinal Center B Cells and Plasma Cell Precursors in the Blood of Children with Systemic Lupus Erythematosus. The Journal of Immunology, 167, 2361-2369. https://doi.org/10.4049/jimmunol.167.4.2361

[18] Van Gent, R., van Tilburg, C.M., Nibbelke, E.E., Otto, S.A., Gaiser, J.F., et al. (2009) Refined Characterization and Reference Values of the Pediatric T- and B-Cell Compartments. Clinical Immunology, 133, 95-107.

[19] Nowbakht, P., Ionescu, M.C., Rohner, A., Kalberer, C.B., Rossy, E., et al. (2005) Ligands for Natural Killer Cell-Activating Receptors Are Expressed upon the Maturation of Normal Myelomonocytic Cells But at Low Levels in Acute Myeloid Leukemias. Blood, 105, 3615-3622. https://doi.org/10.1182/blood-2004-07-2585

[20] Ebihara, T., Masuda, H., Akazawa, T., Shingai, M., Kikuta, H., et al. (2007) Induction of NKG2D Ligands on Human Dendritic Cells by TLR Ligand Stimulation and RNA Virus Infection. International Immunology, 19, 1145-1155. https://doi.org/10.1093/intimm/dxm073

[21] Kloss, M., Decker, P., Baltz, K.M., Baessler, T., Jung, G., et al. (2008) Interaction of Monocytes with NK Cells upon Toll-Like Receptor-Induced Expression of the NKG2D Ligand MICA. The Journal of Immunology, 181, 6711-6719. https://doi.org/10.4049/jimmunol.181.10.6711

[22] Chu, T., Tyznik, A.J., Roepke, S., Berkely, A.M., Woodward, D.A., et al. (2013) Bystander-Activated Memory CD8 T Cells Control Early Pathogen Load in an InnateLike, NKG2D-Dependent manner. Cell Reports, 3, 701-708.

[23] Ziegler-Heitbrock, L., Ancuta, P., Crowe, S., Dalod, M., Grau, V., et al. (2010) Nomenclature of Monocytes and Dendritic Cells in blood. Blood, 116, e74-e80. https://doi.org/10.1182/blood-2010-02-258558

[24] Li, Y., Lee, P.Y. and Reeves, W.H. (2010) Monocyte and Macrophage Abnormalities in Systemic Lupus Erythematosus. Archivum Immunologiae et Therapia Experimentalis, 58, 355-364. https://doi.org/10.1007/s00005-010-0093-y 
[25] Mozaffarian, N., Wiedeman, A.E. and Stevens, A.M. (2008) Active Systemic Lupus Erythematosus Is Associated with Failure of Antigen-Presenting Cells to Express Programmed Death Ligand-1. Rheumatology, 47, 1335-1341. https://doi.org/10.1093/rheumatology/ken256

[26] Burbano, C., Vasquez, G. and Rojas, M. (2014) Modulatory Effects of CD14+CD16++ Monocytes on CD14++CD16- Monocytes: A Possible Explanation of Monocyte Alterations in Systemic Lupus Erythematosus. Arthritis \& Rheumatology, 66, 3371-3381. https://doi.org/10.1002/art.38860

[27] Cerboni, C., Zingoni, A., Cippitelli, M., Piccoli, M., Frati, L., et al. (2007) AntigenActivated Human T Lymphocytes Express Cell-Surface NKG2D Ligands via an ATM/ATR-Dependent Mechanism and Become Susceptible to Autologous NK-Cell Lysis. Blood, 110, 606-615. https://doi.org/10.1182/blood-2006-10-052720

[28] Spada, R., Rojas, J.M., Perez-Yague, S., Mulens, V., Cannata-Ortiz, P., et al. (2015) NKG2D Ligand Overexpression in Lupus Nephritis Correlates with Increase NK Cell Activity and Differentiation in Kidneys But Not in the Periphery. Journal of Leukocyte Biology, 97, 583-598. https://doi.org/10.1189/jlb.4A0714-326R

[29] Gambelunghe, G., Gerli, R., Bocci, E.B., Del Sindaco, P., Ghaderi, M., et al. (2005) Contribution of MHC Class I Chain-Related A (MICA) Gene Polymorphism to Genetic Susceptibility for Systemic lupus Erythematosus. Rheumatology, 44, 287292. https://doi.org/10.1093/rheumatology/keh459

[30] Yoshida, K., Komai, K., Shiozawa, K., Mashida, A., Horiutchi, T., et al. (2011) Role of the MICA Polymorphism in Systemic Lupus Erythematosus. Arthritis \& Rheumatology, 63, 3058-3066. https://doi.org/10.1002/art.30501

[31] Fiore, N., Castellano, G., Blasi, A., Capobianco, C., Loverre, A., et al. (2008) Immature Myeloid and Plasmacytoid Dendritic Cells Infiltrate Renal Tubulointerstitium in Patients with Lupus Nephritis. Molecular Immunology, 45, 259-265.

\section{Non-Standard Abbreviations}

NKG2DL, NKG2D ligand; MICA and MICB, MHC class I-related chains A and B; ULBP, UL-16 binding protein; SLE, systemic lupus erythematosus; jSLE, juvenile-onset SLE; HC, healthy control. 


\section{Appendix. Supplementary Data}

(a)
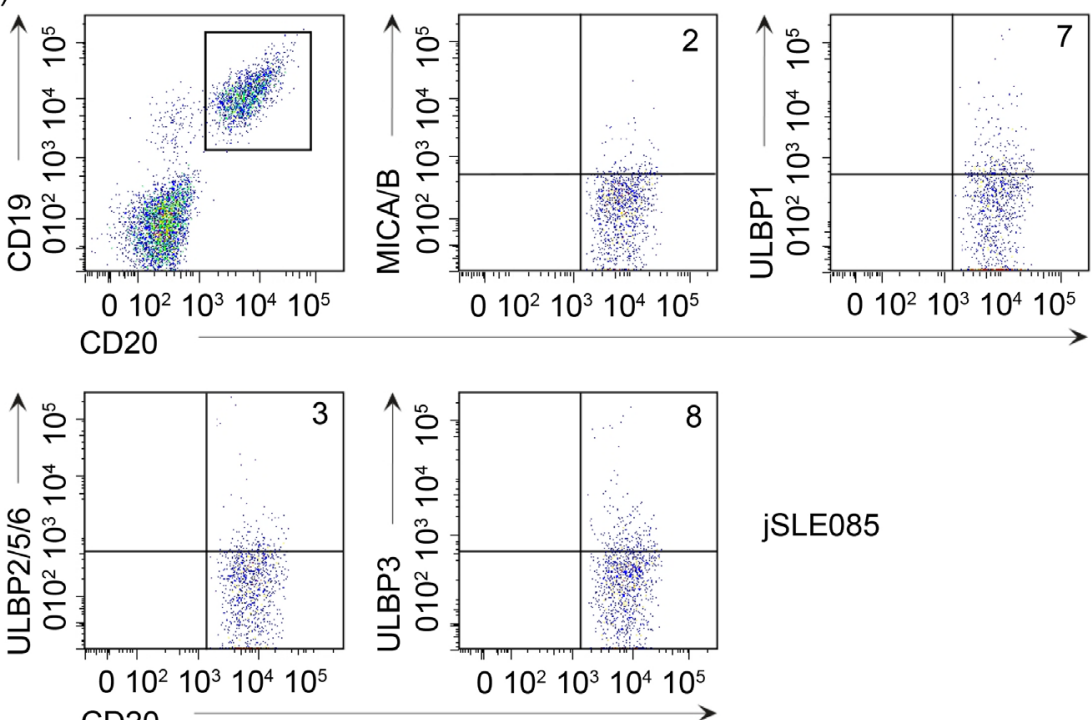

jSLE085

(b) CD20
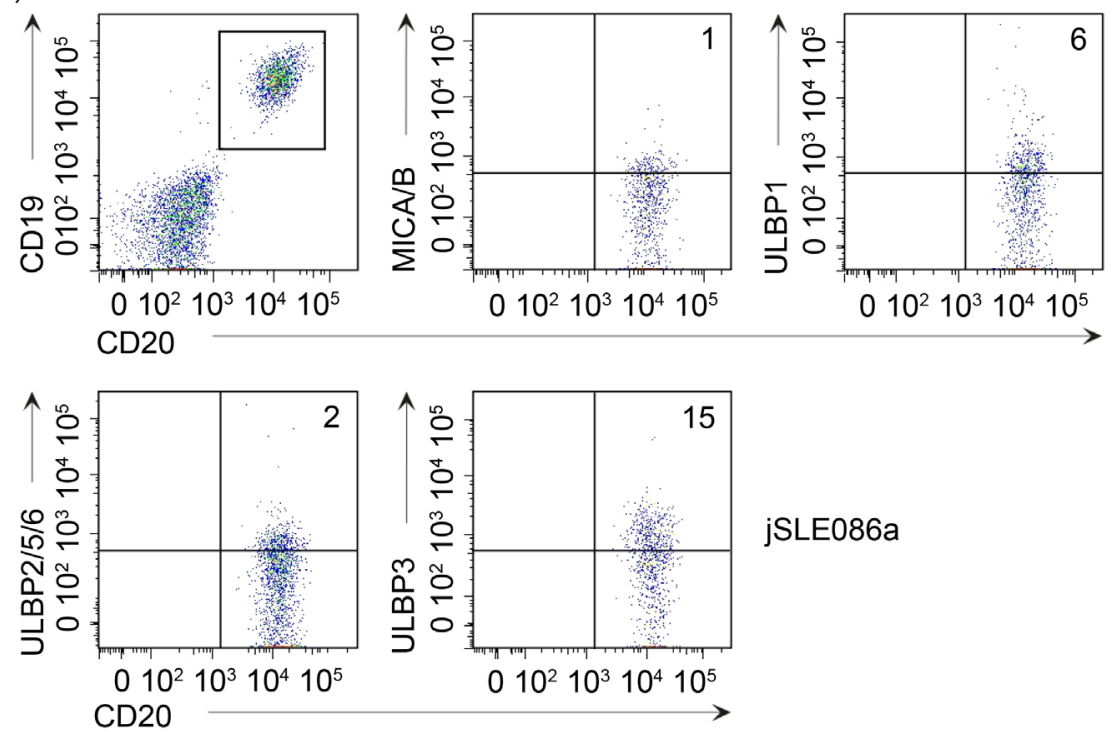

jSLE086a

Figure S1. Example NKG2D ligand profiles of juvenile-onset SLE B cells. Flow cytometry dot plots displaying gating strategy (upper left dot plots) for, and anti-NKG2D ligand monoclonal antibody staining of CD19/CD20-defined peripheral blood B cells from juvenile-onset SLE patient jSLE085 (a) and jSLE086 (b). Numbers in quadrants represent \% of total $\mathrm{CD} 19^{+} \mathrm{CD} 20^{+}$cells. 

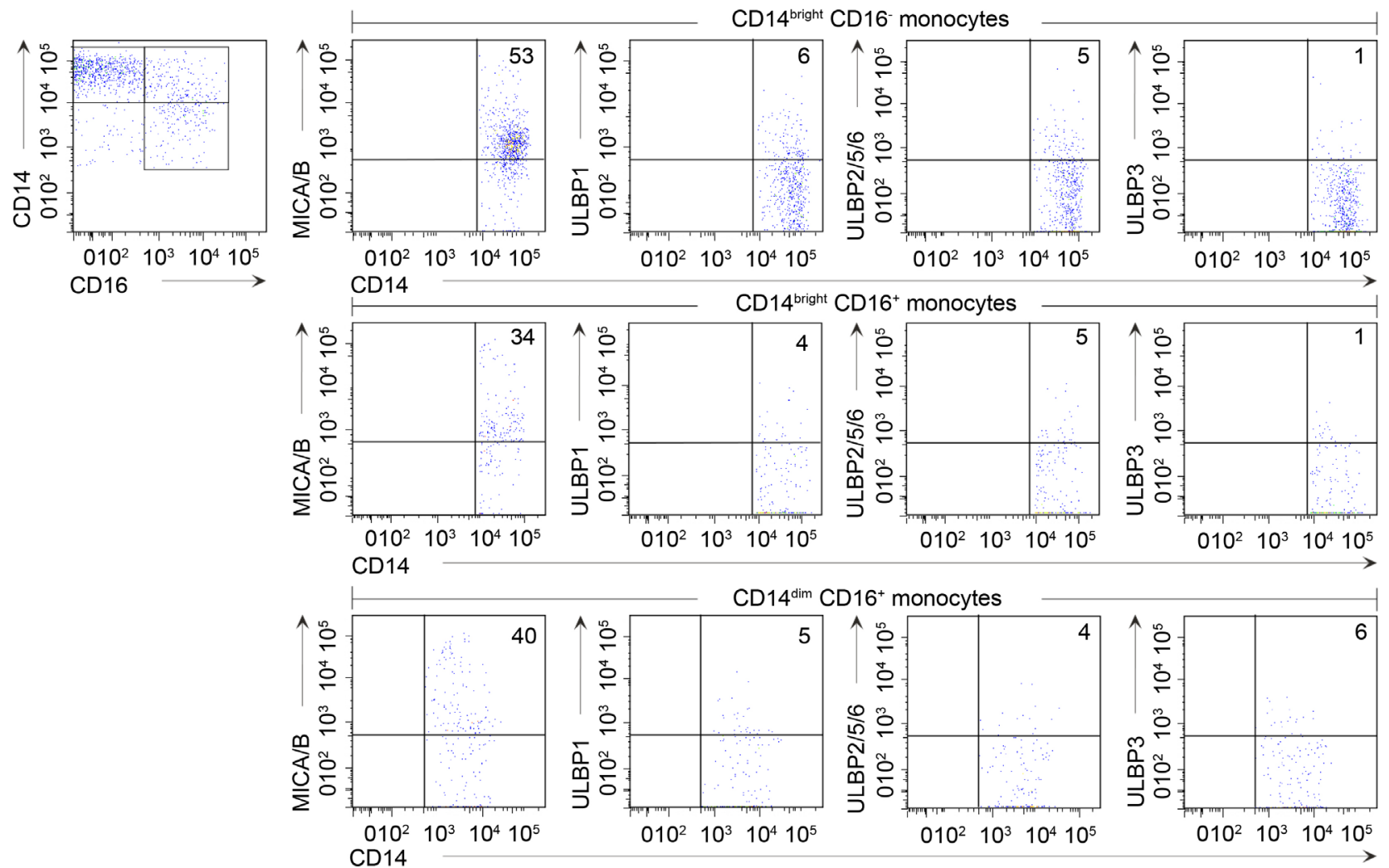

Figure S2. Example multicolor flow cytometry dot plots displaying gating strategy (upper left dot plot) for, and anti-NKG2D ligand monoclonal antibody staining of CD14/CD16-defined peripheral blood monocytes from a juvenile-onset SLE patient (jSLE040). Numbers in quadrants represent $\%$ of total $\mathrm{CD} 14^{\text {bright }} \mathrm{CD} 16^{-}, \mathrm{CD} 14^{\text {bright }} \mathrm{CD} 16^{+}$, and $\mathrm{CD} 14^{\text {dim }} \mathrm{CD} 16^{+}$monocytes. 


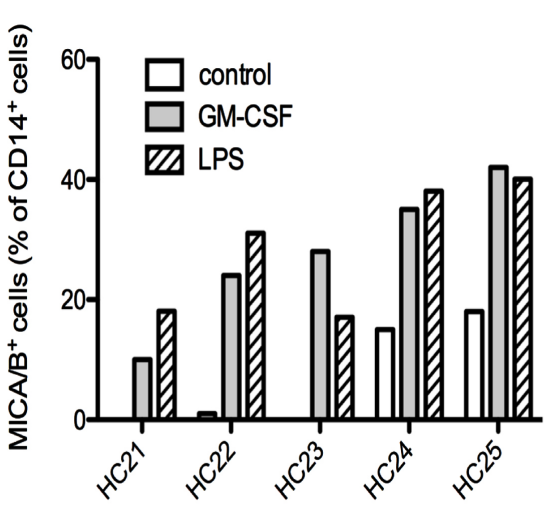

(a)

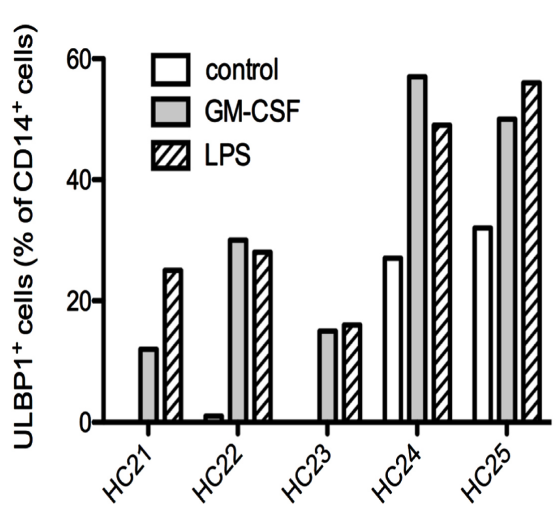

(c)

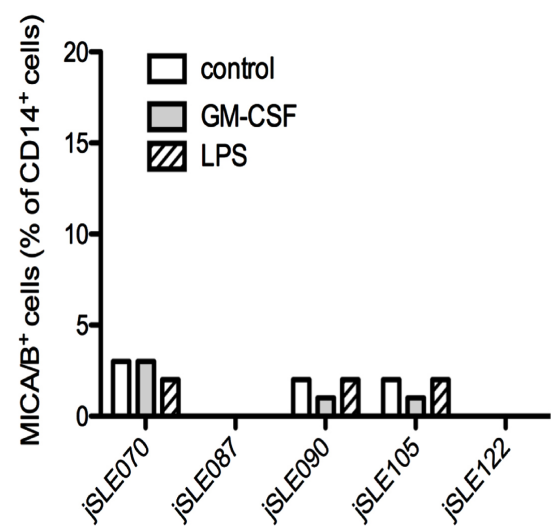

(b)

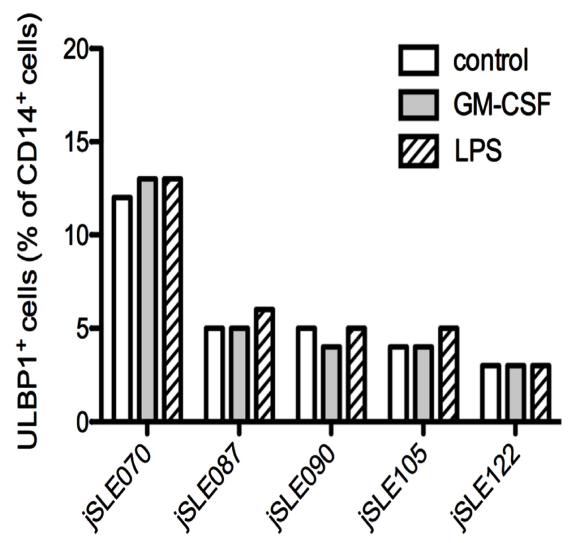

(d)

Figure S3. Failure to induce NKG2DL expression in juvenile-onset SLE monocytes. Graphic display of proportions (in \%) of HC ((a) (c)) and jSLE ((b) (d)) CD14 $4^{+}$monocytes expressing MICA/B ((a) (b)) and ULBP1 ((c) (d)) ligands after a $24 \mathrm{hr}$ exposure to medium control (open bars), GM-CFS (grey bars), or LPS (shaded bars).

Submit or recommend next manuscript to SCIRP and we will provide best service for you:

Accepting pre-submission inquiries through Email, Facebook, LinkedIn, Twitter, etc. A wide selection of journals (inclusive of 9 subjects, more than 200 journals)

Providing 24-hour high-quality service

User-friendly online submission system

Fair and swift peer-review system

Efficient typesetting and proofreading procedure

Display of the result of downloads and visits, as well as the number of cited articles

Maximum dissemination of your research work

Submit your manuscript at: http://papersubmission.scirp.org/

Or contact oji@scirp.org 